\title{
Mitigating the risk of opioid abuse through a balanced undergraduate pain medicine curriculum
}

This article was published in the following Dove Press journal:

Journal of Pain Research

3 December 2013

Number of times this article has been viewed

\author{
Patricia K Morley-Forster ${ }^{1,2}$ \\ Joseph V Pergolizzi ${ }^{3-5}$ \\ Robert Taylor $\mathrm{Jr}^{5}$ \\ Robert A Axford-Gatley ${ }^{6}$ \\ Edward M Sellers ${ }^{7}$ \\ 'Department of Anesthesia and \\ Perioperative Medicine, University \\ of Western Ontario, London, ON, \\ Canada; ${ }^{2}$ Outpatient Pain Clinic, \\ St Joseph's Hospital, London, ON, \\ Canada; ${ }^{3}$ Department of Medicine, \\ Johns Hopkins University School \\ of Medicine, Baltimore, MD, USA; \\ ${ }^{4}$ Department of Pharmacology, \\ Temple University School of \\ Medicine, Philadelphia, PA, USA; \\ ${ }^{5}$ NEMA Research Inc, Naples, FL, \\ USA; ${ }^{6} \mathrm{Clinical}$ Content and Editorial \\ Services, Complete Healthcare \\ Communications, Inc, Chadds Ford, \\ PA, USA; ${ }^{7}$ DL Global Partners Inc, \\ Toronto, ON, Canada
}

Correspondence: Patricia K MorleyForster

Medical Director, Outpatient Pain Clinic, St Joseph's Hospital, Room B3-628,

268 Grosvenor Street, London,

Ontario N6A 4V2, Canada

$\mathrm{Tel}+$ I 5196466000 (ext 65065)

Email pat.morley-forster@sjhc.london. on.ca

\begin{abstract}
Chronic pain is highly prevalent in the United States and Canada, occurring in an estimated $30 \%$ of the adult population. Despite its high prevalence, US and Canadian medical schools provide very little training in pain management, including training in the safe and effective use of potent analgesics, most notably opioids. In 2005, the International Association for the Study of Pain published recommendations for a core undergraduate pain management curriculum, and several universities have implemented pilot programs based on this curriculum. However, when outcomes have been formally assessed, these initiatives have resulted in only modest improvements in physician knowledge about chronic pain and its treatment. This article discusses strategies to improve undergraduate pain management curricula and proposes areas in which those efforts can be augmented. Emphasis is placed on opioids, which have great potency as analgesics but also substantial risks in terms of adverse events and the risk of abuse and addiction. The authors conclude that the most important element of an undergraduate pain curriculum is clinical experience under mentors who are capable of reinforcing didactic learning by modeling best practices.
\end{abstract}

Keywords: chronic pain, curricular content, medical education, opioids, pain education, pain knowledge, physician training, teaching

\section{Introduction}

Chronic pain is reported in an estimated $30 \%$ of adults (aged $\geq 18$ years) in the United States. ${ }^{1}$ The need to treat pain is nearly universal across medical specialties and primary care, and expert consensus guidelines have been developed for its management in many patient populations, including surgical patients, ${ }^{2}$ cancer patients, ${ }^{3}$ the elderly, ${ }^{4}$ patients with pain related to osteoarthritis, ${ }^{5}$ chronic low back pain, ${ }^{6}$ neuropathic pain, ${ }^{7}$ and cardiovascular (eg, anginal) pain. ${ }^{8}$ Nonetheless, recent surveys of US and Canadian undergraduate medical school curricula call into question the adequacy of current training in pain management. ${ }^{9,10}$

US medical schools provide surprisingly little undergraduate training in pain management, opioid prescribing, and addiction medicine. Only $30 \%$ of US medical schools require instruction in opioid prescribing, and $10 \%$ require instruction about abuse and addiction. ${ }^{9}$ The mean number of hours devoted to undergraduate education in pain management in US medical schools was 11.1 hours per program (range, 1-31 hours). ${ }^{9}$ Similarly, only $32 \%$ of Canadian medical schools provide formal pain management content in their undergraduate programs. ${ }^{10}$ Canadian veterinary schools devote five-fold more hours (mean 87 hours, range 27-200) to pain management education than do Canadian medical schools (mean 16 hours, range 0-38). Efforts 
to improve medical school curricula are therefore essential, not only to improve the control of pain but to ensure that prescribers in every care setting involving pain management are aware of the adverse events (AEs) and potential for abuse and addiction associated with pain medications.

This article reviews current initiatives intended to improve undergraduate medical school curricula for pain management and proposes additional components for incorporation into medical education. The scope of this review is limited to pain management curricula in North American medical schools, although the authors believe that effective training in pain management is an international priority. Emphasis is placed on the importance of training in the use of opioid analgesics, because these agents are potent pain medications with significant potential for AEs, including abuse and addiction. ${ }^{6,11,12}$

\section{Undergraduate pain curricula: recent efforts International Association for the Study of Pain curriculum}

In 2005, the International Association for the Study of Pain (IASP) published the third edition of its Core Curriculum for Professional Education in Pain. ${ }^{13}$ Topics include the basics of pain physiology, the assessment of pain, and pharmacologic as well as nonpharmacologic treatments, including cognitive behavioral therapy, physical rehabilitation, and surgery. The curriculum covers management strategies for different types of pain, including acute and chronic pain and several noncancer pain conditions for which there are accepted guidelines (eg, osteoarthritis and back pain). It also addresses pain management in specific populations, including older patients, pediatric patients (infants, children, and adolescents), patients with cognitive impairment that limits their ability to communicate, substance abusers, and individuals living in poverty or political turmoil.

Opioids are addressed in a separate module, with an emphasis placed on opioid pharmacology. Topics include the basics of opioid receptor binding, tolerance and dependence, factors contributing to individual variability of response to specific opioids, pharmacokinetics, metabolism, routes of administration, AEs and toxicities, and addiction. Undergraduate pain management curricula based on the IASP recommendations have been implemented at several medical schools, including the University of Toronto, Toronto, ON, Canada; ${ }^{14}$ Virginia Commonwealth University, Richmond, VA, USA; ${ }^{15}$ and Johns Hopkins University, Baltimore, MD,
USA. ${ }^{16}$ The programs at these institutions are discussed as examples of the varied ways in which the IASP curriculum has been implemented for undergraduate students. Our search for innovative curricula in pain management and opioid therapy also identified two undergraduate initiatives ${ }^{17,18}$ for which implementation trials have not been published and one program designed for graduate students. ${ }^{19}$ These are described in Table 1.

It is valuable to compare undergraduate curricula with the graduate pain curriculum put forth by the Accreditation

Table I Core elements of pain curricula that address the management of opioids

\begin{tabular}{|c|c|}
\hline Curriculum & Core elements \\
\hline $\begin{array}{l}\text { Columbia University } \\
\text { College of Physicians } \\
\text { and Surgeons }{ }^{17}\end{array}$ & $\begin{array}{l}\text { - General CNCP instruction }(2 \mathrm{~h}) \\
\text { - Case-based discussions with discussion } \\
\text { questions, handouts, and links to screening } \\
\text { instruments and other course materials } \\
\text { online }\end{array}$ \\
\hline Hurley Medical & Week I-2 (5 h) \\
\hline Center/Michigan & - Knowledge pretest \\
\hline State University ${ }^{19}$ & $\begin{array}{l}\text { - Pharmacological management plan workshop } \\
\text { - Pharmacology of short-acting and long-acting } \\
\text { opioids, addiction screening, indications for } \\
\text { referral } \\
\text { - Legal considerations for prescribing } \\
\text { - Urine drug test interpretation } \\
\text { - Feedback on written management plan based } \\
\text { on case scenario } \\
\text { Week } 3 \text { ( } 2 \text { h) } \\
\text { - Role play group activity } \\
\text { - Case discussions } \\
\text { Outcome measurements } \\
\text { - Knowledge post-test } \\
\text { - Observation by mentor during live clinical } \\
\text { encounter with immediate feedback }\end{array}$ \\
\hline $\begin{array}{l}\text { University of } \\
\text { Washington School } \\
\text { of Medicine }{ }^{18}\end{array}$ & $\begin{array}{l}\text { Required courses } \\
\text { - Year I ( } 3 \text { h): physician/psychologist lecture, } \\
\text { interaction with invited pain patients } \\
\text { - Year } 2 \text { ( } 5 \text { h): principles of pain, case-based } \\
\text { pharmacology, opioids/NSAIDs, addiction } \\
\text { management } \\
\text { - Year } 3 \text { (5 h): active participation in pain } \\
\text { medicine case consultation } \\
\text { - Year } 4 \text { (2 h): pain case-based learning, } \\
\text { opioid Q\&A } \\
\text { Elective courses } \\
\text { - Years I-2 (32 h): preceptorship in pain clinic } \\
\text { - Year 3: pain case-based presentation/ } \\
\text { treatment planning } \\
\text { - Year } 4 \text { (I44 h): anesthesia pain medicine } \\
\text { (hospital based), acute/interventional pain } \\
\text { treatment } \\
\text { - Year } 4 \text { (I h): inpatient ordering of opioids } \\
\text { (capstone session) }\end{array}$ \\
\hline
\end{tabular}

Abbreviations: $\mathrm{CNCP}$, chronic noncancer pain; NSAID, nonsteroidal anti-inflammatory drug; Q\&A, question and answer. 
Council for Graduate Medical Education (ACGME), which is intended to provide a specialist level of training in pain management. The ACGME pain curriculum has core elements in common with the IASP undergraduate curriculum, such as understanding the anatomic, pathophysiologic, and psychological bases of pain and pain relief; clinical pharmacology; assessment of pain; and management of the risks of analgesic abuse and addiction. However, the ACGME curriculum differs from the IASP curriculum in its emphasis on the need for clinical experience and putting didactic knowledge into practice. The ACGME curriculum addresses this goal through mentored clinical experiences that reinforce didactic learning and provide progressive responsibility, conditional independence, and a supervisory role in patient care based on patient needs and the skills of the specialist in training. ${ }^{20}$

What is taught in the classroom on pain management needs to be put into practice. ${ }^{21}$ The ultimate test of a new pain curriculum is improved patient care, a goal that is best achieved when there is some strategy for follow-up to ensure that students comply with the curriculum in the clinical/hospital setting. Evaluating the outcome of a new pain curriculum delivered in the classroom should include assessment of clinical skills. This requires skillful mentoring by attending physicians and residents who agree with the curriculum and use it in the clinic as a basis for instructing students in pain management.

\section{University of Toronto}

A didactic program based on the IASP curriculum was implemented at the University of Toronto with a mandatory 5-day, 20-hour course presented to 190 undergraduate medical students and 350 students in allied health disciplines (pharmacy, $\mathrm{n}=128$; physical or occupational therapy, $\mathrm{n}=121$; dentistry, $\mathrm{n}=70$; and nursing, $\mathrm{n}=31$ ). ${ }^{14}$ In addition to lectures, the course included support from faculty members with knowledge of information technology, e-learning, library science, and case study development. Participants were given written materials on pain and its management before program initiation. Large-group sessions were conducted by pain specialists to provide an overview of pain mechanisms, clinical challenges, and World Health Organization classification of health, functioning, and disability. Participants were introduced to actual chronic pain patients, who told their stories. In subsequent small-group sessions, students prepared a management strategy for a "standardized cancer patient" (played by an actor) under the direction of specialists from all the medical disciplines involved. However, the program involved no true clinical experience with students managing real patients under expert mentorship.
Participants completed the Revised Pain Knowledge and Attitudes Questionnaire before and after the course. ${ }^{14,22,23}$ Upon completion, mean questionnaire scores improved from $66 \%$ before the course to $83 \%$ after the course, a statistically significant $17 \%$ improvement $(P<0.001)$. Scores improved by more than $40 \%$ in several areas, including opioid use in the elderly and patients with chronic noncancer pain, management of opioid-related constipation, and physiologic mechanisms of analgesia. The magnitude of improvement in opioid prescribing suggests that the course successfully addressed unmet needs.

\section{Virginia Commonwealth University}

The Virginia Commonwealth University Chronic Nonmalignant Pain Management curriculum is an Internet-based educational program divided into six modules: 1) Overview and Assessment of Chronic Nonmalignant Pain, 2) Treatment of Chronic Nonmalignant Pain, 3) Common Pain Syndromes: Fibromyalgia, 4) Common Pain Syndromes: Neuropathic Pain, 5) Identifying and Meeting Challenges, and 6) Legal and Regulatory Aspects of Prescribing Controlled Substances. ${ }^{15}$ Site structure is based on learning objectives, with each objective supported by case-based self-assessment questions, tabbed pages with practice resources, and ongoing feedback to reinforce learning. There is also a section that provides "optional advanced content". Participant performance is assessed by a series of questions presented before and after completion of the program. As with the University of Toronto curriculum, there was no clinical experience or mentorship in the Virginia Commonwealth University program.

The curriculum was administered during the 2006-2007 academic year to 161 undergraduate medical students and 278 residents. Participants correctly answered 62.3\% of the preprogram questions and $64.0 \%$ of the postprogram questions. Eighty-nine percent of participants stated they would use the resources provided again, 74.7\% stated they would change their practices and behaviors based on curriculum content, and $95.7 \%$ said they would recommend the curriculum to colleagues. However, the slight improvement in test scores after completion of the program does not suggest that it improved knowledge.

\section{Johns Hopkins University}

A study in 118 undergraduate medical students at Johns Hopkins University Medical School assessed a 4-day course based on topics identified in IASP guidelines, other medical school curricula, and medical certification examinations. These topics included pain neurobiology; the human and social 
costs of pain; the clinical assessment of pain; pharmacologic and nonpharmacologic pain management; interventional approaches to pain management, acute pain, chronic pain, pediatric and geriatric pain, and cancer pain; the impacts of culture and ethnicity on pain; and the medicolegal aspects of pain management. ${ }^{16}$ This 4-day course provided 18 hours of a 35-hour overall program of pain management instruction, with the remaining course content delivered as part of other areas in the 4-year medical school curriculum.

Sixty percent or less of the 4-day course consisted of lectures; the rest consisted of workshop activities with faculty members. The lectures introduced basic concepts of pain management, including peripheral pathophysiology of pain, central pain processing and hyperalgesia, and the clinical psychology of pain. Learning laboratories covered pain psychophysics, medication prescribing, and medicolegal aspects of pain management. Day 3 of the Johns Hopkins course focused on chronic pain and opioid use. Topics in this course section included risk assessment for opioid use, pain pathophysiology, opioid pharmacology, and societal duties of the prescriber. ${ }^{16}$ Postprogram assessments included multiple choice testing, a brief assessment portfolio, and a paired work assignment test wherein students applied their knowledge of pain to pain problems. Real-world experience with patients was not a part of the 4-day program.

Most of the participants expressed satisfaction with the course and felt they had an enhanced appreciation of "key challenges of providing pain care, eg, assessment, impairment, abuse, and addiction". ${ }^{16}$ Following completion of the 4-day course, the mean (SD) score on the multiple choice testing was $75 \%$ (eleven), and the mean score on assessment portfolio was $87 \%(12.2)$. However, the absence of a test to capture baseline knowledge makes it unclear how much the program fostered new understanding.

\section{Summary}

Although these examples suggest that even a short, focused program of study can produce improvement in test scores on the topic of pain management and opioid therapy, a problem common to each program is the lack of clinical exposure and mentoring. The typical model of undergraduate medical education is to conduct didactic teaching in tandem with clinical experience.

In the area of pain management, the quality of mentoring is a key consideration. Given the widespread weakness of pain management education in North American medical schools, undergraduate students may not encounter peers and mentors who follow best practices. A survey of
1,000 randomly selected Canadian primary care physicians revealed that the majority lacked confidence in their skills in prescribing opioids and were concerned about facilitating abuse or addiction. ${ }^{24}$ More troublesome, a recent survey of internal medicine residents at a US university health system found that the majority scored poorly on a written examination of therapeutic drug monitoring skills for chronic pain patients taking opioids, yet rated themselves as confident in these skills. ${ }^{25}$ Indeed, among male respondents there was an inverse relationship between competence and selfconfidence. ${ }^{26}$ Even among physicians practicing in a specialty pain clinic, a retrospective analysis of a urine drug screening program found that $55 \%$ continued to prescribe opioids in the same manner after risk factors or inappropriate opioid use were identified. ${ }^{27}$

\section{Key elements for an undergraduate pain curriculum}

Gaps in the present pain management curricula are not a product of a lack of information but a failure to disseminate currently available knowledge to medical students. The curricula proposed and implemented in the previous examples represent systematic efforts to bridge the gap between theory and practice. Building on the IASP recommendations, the following sections describe areas in which an undergraduate curriculum might be further improved, with the goal of making pain medicine a larger part of the curriculum. However, the curriculum must include experiential opportunities with mentoring by competent clinicians. The necessity of combining didactic and clinical components in undergraduate pain curricula was reflected in a 2013 survey of members of the American Academy of Pain Medicine, which asked participants to rank the priority of learning objectives for a comprehensive pain management curriculum. ${ }^{28}$ Although the top ten priority items included the essential knowledge base of pain neurobiology, nonpharmacologic treatments, and the clinical pharmacology of opioids and neuromodulating agents, the highest-ranked components were all clinical skills. Compassionate care and empathy were the top priority, followed by examination skills and communication. The leading message was that the ideal undergraduate medical school pain curriculum should be highly clinical. ${ }^{28}$ The medical students need to be exposed to empathic physician mentors from multiple disciplines who have integrated their knowledge base with best practice guidelines and motivational interviewing; in other words, those who model the "art" of medicine.

We believe that an effective curriculum should focus on traditionally underemphasized areas such as clinical 
pharmacology, the psychology of addiction, responsible prescribing of opioids, and recognizing and managing aberrant drug-related behavior.

\section{Physiology of pain}

A comprehensive pain management curriculum will differentiate between various types of pain, which may be nociceptive, neuropathic, or mixed. Pain may also be central or peripheral, acute or chronic, and cancer-related or noncancer-related. Accurate diagnosis of the pain syndrome is a prerequisite to the rational use of pharmacotherapies.

Pain classification may not only dictate the appropriate therapy but also influence physician attitudes toward it. Depression is highly prevalent in patients with chronic pain. ${ }^{29}$ Depression substantially increases the risk that acute back pain will become chronic. ${ }^{30}$ Nonetheless, depression tends to be underdiagnosed, and therefore potentially undertreated, in patients with pain. ${ }^{31}$

\section{Psychosocial aspects of pain}

The Association of American Medical Colleges recommends medical school instruction on the role of behavioral and social sciences in medicine. ${ }^{32}$ With respect to pain management, these guidelines endorse a healthy mind-body approach to care that incorporates stress reduction, relaxation, treatment of anxiety, treatment of substance abuse, and sobriety maintenance. ${ }^{32}$ Emphasis on the psychological and social aspects of pain is of critical importance because chronic pain predisposes individuals to psychiatric comorbidities, particularly depression, ${ }^{33,34}$ and because pain and psychiatric comorbidities such as depression, anxiety, and personality disorders increase the risk of substance abuse. ${ }^{35-41}$ Moreover, some patients, particularly the elderly, may express depression or anxiety as a somatic complaint. Through a somatic complaint of pain, the patient obtains access to care without acknowledging the psychological distress underlying it. It is therefore essential to address the somatic complaint and the psychiatric factors underlying it to obtain an adequate resolution of symptoms. ${ }^{42}$

There are substantial differences in the psychosocial aspects of pain based on race, economic status, and other factors that are reflected in the patient's experience of pain and attitudes toward treatment, and in the physician's interpretation of the patient's symptoms and attitudes toward treating them. For example, clinicians are more likely to underestimate pain in African American patients and overestimate pain severity in white patients. ${ }^{43}$ African Americans are less likely to receive opioid therapy. ${ }^{44,45}$ The extent to which this is a product of a lack of physician knowledge about racial differences in pain experience, physician bias, or both falls beyond the scope of this paper. However, a comprehensive medical school curriculum will introduce future clinicians to the concept that both patient and clinician perceptions influence the presentation of pain and its treatment.

\section{Multidisciplinary pain management approach}

According to a report prepared for the United States Department of Health and Human Services, ${ }^{46}$ a multidisciplinary approach to pain management incorporates four central components: medical therapy for the patient's wellbeing, which includes medication management; behavioral therapy (eg, cognitive behavioral therapy) to address the psychosocial aspects of patient care; physical reconditioning, focused on physical or occupational therapy, exercise, stretching, and strengthening; and education, with selfmanagement as the focus.

The IASP curriculum concurs that effective pain management is multimodal and multidisciplinary, incorporating nonpharmacologic treatments such as physical therapy and cognitive behavioral therapy, as well as nerve blocks and surgical interventions for more severe pain. ${ }^{13}$ An expert panel of clinicians has developed an online continuing medical education program for a multidisciplinary approach to chronic pain management. ${ }^{47} \mathrm{~A}$ balanced approach to pain management that corrects misconceptions about chronic pain and addresses psychiatric comorbidities might lessen the use of opioids in patients at risk of substance abuse. This approach is well suited for initial education in a medical school setting as well as for continuing medical education.

\section{Pharmacology of pain Nonopioid analgesics}

Clinical pharmacology is generally underemphasized in medical school curricula, and this applies not only to opioids but to all pharmacotherapies. A proper understanding of mechanisms of action is essential for selecting appropriate analgesics for specific patient populations and for limiting exposure to medications with the potential for misuse.

Acetaminophen is a weak inhibitor of the cyclooxygenase (COX) enzymes and acts centrally by mechanisms that are not clearly understood but are believed to include inhibition of prostaglandin synthesis. ${ }^{48}$ Given its lack of a potent anti-inflammatory effect, the IASP curriculum recommends acetaminophen only for headaches and as an antipyretic. ${ }^{13}$ 
Tricyclic antidepressants and serotonin-norepinephrine reuptake inhibitors boost levels of neurotransmitters involved in neuropathic pain or pain with a neuropathic component. ${ }^{49}$ Nonsteroidal anti-inflammatory drugs (NSAIDs) inhibit the COX-1 and COX-2 enzymes, with COX-2 inhibition providing most of their anti-inflammatory effects. ${ }^{50}$

Given their mechanisms of action, it is logical that NSAIDs and COX-2 inhibitors are recommended for inflammatory conditions such as back pain or osteoarthritis but not neuropathic pain. Similarly, tricyclic antidepressants are considered first-line therapies for neuropathic pain, whereas tricyclics and serotonin-norepinephrine reuptake inhibitors are considered primarily adjunctive therapies in inflammatory conditions. Mechanisms influencing nociceptive pain and the monoamine system explain the broad indications for opioids and also provide a rationale for opioid/antidepressant combinations, such as tapentadol. ${ }^{51}$

\section{Opioid analgesics}

Medical students should receive a comprehensive introduction to opioid pharmacology. Opioid receptor affinity predicts aspects of efficacy and tolerability such that patients experiencing inadequate analgesia or poor tolerability with one opioid may benefit from a switch to another opioid with affinity for a different opioid receptor. For example, an opioid with $\kappa$-opioid receptor affinity (eg, oxycodone) may be more likely to cause dysphoria than an opioid that works primarily at the $\mu$-opioid receptor (eg, hydromorphone or oxymorphone)..$^{52}$

Opioid therapy must be tailored to the needs of special populations, including the elderly, women versus men, pregnant women, patients with psychiatric comorbidities, and adolescents. For example, patients aged $\geq 65$ years typically require a lower opioid dose compared with younger patients, ${ }^{53,54}$ are more susceptible to respiratory depression, and are less likely to experience nausea and vomiting. ${ }^{55}$ Women are more likely than men to experience nausea and vomiting $^{55}$ during opioid therapy and are more susceptible to analgesic effects of opioids with activity at the $\kappa$-opioid receptor. ${ }^{56}$ Dose adjustments in older patients and women are likely to be necessary.

As discussed previously, patients with psychiatric comorbidities are more likely to abuse opioids, and those taking multiple psychotropic drugs are more likely to experience falls. ${ }^{57}$ Because of an increased risk of abuse, added caution should be exercised when prescribing opioids to adolescents. Risk factors include poor academic performance; a history of risk-taking behaviors; a history of depression; and use of alcohol, tobacco, marijuana, or other substances. ${ }^{58}$

Similarly, the health status of individual patients influences opioid selection. Patients with cardiovascular or respiratory disease should not be prescribed methadone, which may cause QT interval prolongation. ${ }^{59}$ Opioid metabolites can cause $\mathrm{AEs}^{60-63}$ when they accumulate in patients with certain comorbidities (eg, renal ${ }^{64}$ or hepatic ${ }^{65}$ impairment).

Familiarity with opioid formulations is also important because long-acting opioids are generally not indicated for acute pain or for opioid-naive patients. ${ }^{66-68}$

\section{Opioid analgesics: benefits and risks}

When balancing the benefits and risks of opioids, it is important to remember that undertreatment of pain may predispose individuals to psychiatric comorbidities, particularly depression. ${ }^{33,34}$ Both pain and depression increase the risks of substance abuse. ${ }^{35}$

Opioids may provide effective analgesia in patients with chronic noncancer pain such as low back pain, ${ }^{6}$ osteoarthritis, ${ }^{12}$ and neuropathic pain ${ }^{7,11,69}$ that does not respond to other therapies. In fact, based on effect sizes calculated for Osteoarthritis Research Society International guidelines, opioids are the only oral therapy with an effect size $(0.78)$ that approaches the 0.80 threshold for a strong analgesic treatment effect for osteoarthritis pain. Acetaminophen does not meet the threshold for a clinically meaningful effect (effect size, 0.14), and nonselective NSAIDs (effect size, 0.29) and COX-2 inhibitors (effect size, $0.44)$ exert small to moderate analgesic effects for osteoarthritis pain. ${ }^{12}$ There is a need for further research on the longterm efficacy of opioid therapy for chronic noncancer pain, which remains controversial. ${ }^{70}$ A recent systematic review of randomized controlled trials found that although many patients cannot tolerate long-term opioid therapy because of AEs (eg, constipation), those who can tolerate opioids experience clinically meaningful long-term pain relief. ${ }^{71}$ However, it must be emphasized that evidence for the long-term use of opioids for relief of chronic pain is weak. All opioids are associated with risks of nausea and vomiting, somnolence, constipation, dizziness, and respiratory depression, ${ }^{72}$ although individual opioids differ according to pharmacologic differences described previously. Opioids do not cause gastrointestinal bleeding and may not increase cardiovascular risk to the same extent as NSAIDs. As a result, American Heart Association guidelines recommend considering a trial of an opioid rather than NSAID treatment in patients with heightened cardiovascular risk. ${ }^{73}$ 


\section{Opioid abuse}

Clinicians express greater concern about abuse and addiction than they do about other opioid AEs. ${ }^{74,75}$ Strategies for mitigating the risk of opioid abuse have been published in clinical guidelines ${ }^{76,77}$ and must be included in pain management curricula at all levels. ${ }^{13,77}$

\section{Factors predicting the likelihood of opioid abuse}

Methods for assessing the relative risk of a patient to abuse opioids before initiating therapy include interviews to identify a past, current, or family history of substance abuse. ${ }^{78}$ Validated screening tools developed to estimate abuse risk include the revised Screener and Opioid Assessment for Patients with Pain ${ }^{79}$ the Current Opioid Misuse Measure, ${ }^{80}$ and the Opioid Risk Tool.$^{81}$ Clinicians should also consider entering into more formal patient/prescriber treatment agreements to define expectations with respect to treatment goals, compliance monitoring, and steps to be taken in the event of suspected abuse. ${ }^{82}$

\section{Selecting the appropriate formulation, dose, and duration of therapy}

Opioid therapy should be initiated in time-limited trials designed to determine efficacy and safety and gauge patient compliance with the prescribed regimen. There is a growing consensus that administration of a morphine-equivalent dose of $>200 \mathrm{mg} /$ day constitutes high-dose therapy and warrants heightened vigilance to guard against abuse. Canadian guidelines go beyond US guidelines with respect to opioid selection, recommending weak opioids such as tramadol or codeine as the initial agent because of a lower potential for abuse, and caution that the familiarity of abusers with certain opioids (eg, hydromorphone, hydrocodone, and oxycodone) increases their propensity for abuse. ${ }^{77}$

The Canadian guidelines also suggest that long-acting opioids may be preferred over short-acting formulations in older patients to improve compliance with prescribed therapy. ${ }^{77} \mathrm{US}$ guidelines acknowledge that use of long-acting preparations has been proposed as a means of reducing the risk. However, both the US and Canadian guidelines acknowledge that there is no evidence that the around-the-clock analgesia provided by a long-acting opioid formulation actually improves compliance or reduces the risk of abuse. 6,77

The recent introduction of opioid formulations designed to present obstacles to certain methods of abuse (so-called tamper-resistant formulations [TRFs] ${ }^{83}$ should be discussed in a comprehensive undergraduate curriculum. However, because long-term epidemiologic data supporting the ability of these formulations to reduce abuse are lacking, this discussion should concern potential benefits and risks of TRFs, with the most obvious potential risk being overreliance on TRFs in the absence of evidence and in inappropriate patients.

\section{Detection of aberrant drug behavior}

Clinicians need to recognize behaviors suggestive of drug seeking for the purposes of misuse, including requests for opioid dose escalations or reports of lost medications. Urine toxicology screening is recommended as a universal precaution in all opioid-treated patients, ${ }^{84}$ and in one study reduced substance abuse by $50 \% \cdot{ }^{85}$ Nonetheless, only a minority of physicians who prescribe opioids conduct urine drug testing,${ }^{74}$ and many who order urine drug screens have difficulty correctly interpreting the results. ${ }^{86}$

\section{Protocol for response to aberrant drug behaviors}

All physicians prescribing opioids should develop a protocol for response to aberrant drug behaviors. US ${ }^{87}$ and Canadian ${ }^{77}$ guidelines for the use of opioids in chronic pain recommend shorter dispensing intervals and more frequent compliance monitoring using both pill counts and urine drug testing, although the accuracy of current monitoring techniques is not fully established..$^{76}$ It may be preferable to use longacting rather than short-acting formulations ${ }^{82}$ although US guidelines state only that a reduced potential for abuse is a theoretical benefit of long-acting preparations, without conclusive data to support it. ${ }^{87}$ Patients with concurrent pain and confirmed abuse or an identified addiction disorder may be candidates for a structured trial of methadone or buprenorphine. ${ }^{77,87}$ Current addiction to alcohol or nonopioid drugs is considered a contraindication to opioid therapy by some authorities ${ }^{82}$ Continued abuse is always an indication for referral to a drug abuse treatment specialist or facility ${ }^{82,87}$ and may be cause for discontinuation of opioid therapy. ${ }^{87}$

\section{Licensing or regulatory requirements}

Undergraduate curricula should prepare physicians for the reality of increasing legal and regulatory scrutiny of prescribing practices. For example, the American states of Washington and Florida have implemented guidelines that limit opioid dosing for prescribers lacking adequate training, improve patient screening and monitoring, and encourage appropriate follow-up of aberrant drug-related behavior. ${ }^{88,89}$

Recent actions of regulatory bodies reflect recognition that there is a need for physician education; however, these bodies have turned to drug companies rather than medical 
schools to provide the necessary instruction. The US Food and Drug Administration has mandated that pharmaceutical companies that manufacture opioid analgesics develop and implement risk evaluation and mitigation strategies, which include prescriber training on the safe and effective use of opioids..$^{90}$ One potential weakness of risk evaluation and mitigation strategies is that they assign responsibility for physician education to parties with a commercial interest in the prescribing of opioids.

The authors consider that there is risk associated with attempting to remedy a lack of education by legislation. If one faces legal or professional penalties for making mistakes in an area where one lacks skills, there exists the temptation simply to not practice in that area rather than acquire the needed skills. From a legislative or regulatory framework, this attitude would have to be countered with penalties for refusing to treat patients with chronic noncancer pain.

\section{Summary}

Many practicing physicians in North America lack skills to effectively manage pain and mitigate the risks of opioid abuse. Improving medical school curricula is the most effective long-term solution to this situation. The curricula should provide guidance on how clinicians can minimize the risk of abuse and diversion of strong analgesics by applying a universal precautions approach to monitoring for all opioidtreated patients. ${ }^{84}$ Prescribers need to know how to enter into controlled substance agreements with their patients, which can define treatment expectations, appropriate opioid use, and steps to be taken in the event of noncompliance with the prescribed regimen.

The authors of this review believe that the most important element of an undergraduate pain curriculum is clinical experience under the mentorship of residents and attending physicians who are capable of reinforcing didactic learning by modeling best practices. An important component of pain management training also is to educate young physicians about the appropriate time to refer to a pain specialist. Given the complexity of pain management, physicians need to know when a clinical situation goes beyond their level of knowledge. Developing a medical student's ability to assess their preparedness for certain clinical situations may be among the most important aspects of undergraduate training.

\section{Acknowledgment}

Editorial support for this manuscript was provided by Jeffrey Coleman, MA, of Complete Healthcare Communications, Inc, Chadds Ford, PA, USA, with funding from Endo Pharmaceuticals Inc, Malvern, PA, USA.

\section{Disclosure}

Dr Morley-Forster has served on an advisory board sponsored by Janssen Ortho Inc, for Nucynta and received a speaker's honorarium on Opioid Prescribing for Community Physicians, sponsored by Purdue Pharma Canada. Dr Pergolizzi is a senior partner in NEMA Research Inc, and has served as a consultant for Johnson \& Johnson, Purdue Pharma LP, Baxter International Inc, and Endo Pharmaceuticals Inc; Dr Taylor is an employee of NEMA Research Inc, and has served as a consultant for Endo Pharmaceuticals Inc; Dr Axford-Gatley is an employee of Complete Healthcare Communications, Inc, which provides editorial services for Endo Pharmaceuticals Inc; Dr Sellers is the President of DL Global Partners, Inc, which provides independent drug development consultation for Endo Pharmaceuticals Inc. The authors contributed to the literature search design, the analysis and interpretation of the literature reviewed in this manuscript, and to the preparation, review, and final approval to submit the manuscript, independent of the funding organization. The authors did not receive any fees or financial support for any activities associated with the manuscript.

\section{References}

1. Johannes CB, Le TK, Zhou X, Johnston JA, Dworkin RH. The prevalence of chronic pain in United States adults: results of an Internet-based survey. J Pain. 2010;11(11):1230-1239.

2. American Society of Anesthesiologists Task Force on Acute Pain Management. Practice guidelines for acute pain management in the perioperative setting: an updated report by the American Society of Anesthesiologists Task Force on Acute Pain Management. Anesthesiology. 2012;116(2):248-273.

3. Ripamonti CI, Bandieri E, Roila F, Group EGW. Management of cancer pain: ESMO Clinical Practice Guidelines. Ann Oncol. 2011; 22(Suppl 6):vi69-vi77.

4. American Geriatrics Society Panel on Pharmacological Management of Persistent Pain in Older Persons. Pharmacological management of persistent pain in older persons. J Am Geriatr Soc. 2009;57(8): 1331-1346.

5. Zhang W, Moskowitz RW, Nuki G, et al. OARSI recommendations for the management of hip and knee osteoarthritis, part II: OARSI evidence-based, expert consensus guidelines. Osteoarthritis Cartilage. 2008;16(2):137-162.

6. Chou R, Qaseem A, Snow V, et al. Diagnosis and treatment of low back pain: a joint clinical practice guideline from the American College of Physicians and the American Pain Society. Ann Intern Med. 2007;147(7):478-491.

7. Attal N, Cruccu G, Baron R, et al. EFNS guidelines on the pharmacological treatment of neuropathic pain: 2010 revision. Eur J Neurol. 2010;17(9):e1113-e1188.

8. Gibler WB, Cannon CP, Blomkalns AL, et al. Practical implementation of the guidelines for unstable angina/non-ST-segment elevation myocardial infarction in the emergency department: a scientific statement from the American Heart Association Council on Clinical Cardiology (subcommittee on acute cardiac care), Council on Cardiovascular Nursing, and Quality of Care and Outcomes Research Interdisciplinary Working Group, in collaboration with the Society of Chest Pain Centers. Circulation. 2005;111(20):2699-2710.

9. Mezei L, Murinson BB. Johns Hopkins Pain Curriculum Development Team. Pain education in North American medical schools. J Pain. 2011;12(12):1199-1208. 
10. Watt-Watson J, McGillion M, Hunter J, et al. A survey of prelicensure pain curricula in health science faculties in Canadian universities. Pain Res Manag. 2009;14(6):439-444.

11. Dworkin RH, O'Connor AB, Audette J, et al. Recommendations for the pharmacological management of neuropathic pain: an overview and literature update. Mayo Clin Proc. 2010;85(Suppl 3):S3-S14.

12. Zhang W, Nuki G, Moskowitz RW, et al. OARSI recommendations for the management of hip and knee osteoarthritis: part III: changes in evidence following systematic cumulative update of research published through Jan 2009. Osteoarthritis Cartilage. 2010;18(4): 476-499.

13. International Association for the Study of Pain. Core Curriculum for Professional Education in Pain. 3rd ed. Seattle, WA: IASP Press; 2005.

14. Watt-Watson J, Hunter J, Pennefather P, et al. An integrated undergraduate pain curriculum, based on IASP curricula, for six health science faculties. Pain. 2004;110(1-2):140-148.

15. Yanni LM, Priestley JW, Schlesinger JB, Ketchum JM, Johnson BA, Harrington SE. Development of a comprehensive e-learning resource in pain management. Pain Med. 2009;10(1):95-105.

16. Murinson BB, Nenortas E, Mayer RS, et al. A new program in pain medicine for medical students: integrating core curriculum knowledge with emotional and reflective development. Pain Med. 2011;12(2):186-195.

17. Gunderson EW, Coffin PO, Chang N, Polydorou S, Levin FR. The interface between substance abuse and chronic pain management in primary care: a curriculum for medical residents. Subst Abus. 2009;30(3): 253-260.

18. Tauben DJ, Loeser JD. Pain education at the University of Washington School of Medicine. J Pain. 2013;14(5):431-437.

19. Elhwairis H, Reznich CB. An educational strategy for treating chronic, noncancer pain with opioids: a pilot test. J Pain. 2010;11(12): 1368-1375.

20. Accreditation Council for Graduate Medical Education. Program requirements for graduate medical education in pain medicine. Available from: http://www.acgme.org/acgmeweb/Portals/0/PFAssets/ ProgramRequirements/sh_multiPainPR707.pdf. Accessed October 1, 2013.

21. Vadivelu N, Mitra S, Hines RL. Undergraduate medical education on pain management across the globe. Virtual Mentor. 2013;15(5):421-427.

22. Unruh A. Teaching student occupational therapists about pain: a course evaluation. Can J Occup Ther. 1995;62(1):30-36.

23. Strong J, Tooth L, Unruh A. Knowledge about pain among newly graduated occupational therapists: relevance for curriculum development. Can J Occup Ther. 1999;66(5):221-228.

24. Wenghofer EF, Wilson L, Kahan M, et al. Survey of Ontario primary care physicians' experiences with opioid prescribing. Can Fam Physician. 2011;57(3):324-332.

25. Starrels JL, Fox AD, Kunins HV, Cunningham CO. They don't know what they don't know: internal medicine residents' knowledge and confidence in urine drug test interpretation for patients with chronic pain. J Gen Intern Med. 2012;27(11):1521-1527.

26. Starrels JL, Becker WC, Alford DP, Kapoor A, Williams AR, Turner BJ. Systematic review: treatment agreements and urine drug testing to reduce opioid misuse in patients with chronic pain. Ann Intern Med. 2010;152(11):712-720.

27. Gupta A, Patton C, Diskina D, Cheatle M. Retrospective review of physician opioid prescribing practices in patients with aberrant behaviors. Pain Physician. 2011;14(4):383-389.

28. Murinson BB, Gordin V, Flynn S, Driver LC, Gallagher RM, Grabois M; Medical Student Education Sub-committee of the American Academy of Pain Medicine. Recommendations for a new curriculum in pain medicine for medical students: toward a career distinguished by competence and compassion. Pain Med. 2013;14(3):345-350.

29. Jann MW, Slade JH. Antidepressant agents for the treatment of chronic pain and depression. Pharmacotherapy. 2007;27(11): 1571-1587.

30. Shaw WS, Means-Christensen AJ, Slater MA, et al. Psychiatric disorders and risk of transition to chronicity in men with first onset low back pain. Pain Med. 2010;11(9):1391-1400.
31. Zastrow A, Faude V, Seyboth F, Niehoff D, Herzog W, Lowe B. Risk factors of symptom underestimation by physicians. J Psychosom Res. 2008;64(5):543-551.

32. Association of American Medical Colleges. Behavioral and social science foundations for future physicians. Available from: https:/www. aamc.org/download/271020/data/behavioralandsocialsciencefoundatio nsforfuturephysicians.pdf. Accessed October 1, 2013.

33. Leo RJ, Pristach CA, Streltzer J. Incorporating pain management training into the psychiatry residency curriculum. Acad Psychiatry. 2003;27(1):1-11.

34. Sullivan MD, Edlund MJ, Steffick D, Unutzer J. Regular use of prescribed opioids: association with common psychiatric disorders. Pain. 2005;119(1-3):95-103.

35. Savage SR, Kirsh KL, Passik SD. Challenges in using opioids to treat pain in persons with substance use disorders. Addict Sci Clin Pract. 2008;4(2):4-25.

36. Cicero TJ, Lynskey M, Todorov A, Inciardi JA, Surratt HL. Co-morbid pain and psychopathology in males and females admitted to treatment for opioid analgesic abuse. Pain. 2008;139(1):127-135.

37. Cohen P, Chen H, Crawford TN, Brook JS, Gordon K. Personality disorders in early adolescence and the development of later substance use disorders in the general population. Drug Alcohol Depend. 2007; 88(Suppl 1):S71-S84

38. Green TC, Grimes Serrano JM, Licari A, Budman SH, Butler SF. Women who abuse prescription opioids: findings from the Addiction Severity Index-Multimedia Version Connect prescription opioid database. Drug Alcohol Depend. 2009;103(1-2):65-73.

39. Morasco BJ, Dobscha SK. Prescription medication misuse and substance use disorder in VA primary care patients with chronic pain. Gen Hosp Psychiatry. 2008;30(2):93-99.

40. Morasco BJ, Turk DC, Donovan DM, Dobscha SK. Risk for prescription opioid misuse among patients with a history of substance use disorder. Drug Alcohol Depend. 2013;127(1-3):193-199.

41. Rieckmann T, McCarty D, Kovas A, et al. American Indians with substance use disorders: treatment needs and comorbid conditions. Am J Drug Alcohol Abuse. 2012;38(5):498-504.

42. Barkin RL, Barkin SJ. Reexamining the elderly patient's presentation with depression. Prim Care Companion J Clin Psychiatry. 2008;10(5):415-416.

43. Staton LJ, Panda M, Chen I, et al. When race matters: disagreement in pain perception between patients and their physicians in primary care. J Natl Med Assoc. 2007;99(5):532-538.

44. Chen I, Kurz J, Pasanen M, et al. Racial differences in opioid use for chronic nonmalignant pain. J Gen Intern Med. 2005;20(7):593-598.

45. Anderson KO, Green CR, Payne R. Racial and ethnic disparities in pain: causes and consequences of unequal care. J Pain. 2009;10(12): 1187-1204.

46. Jeffery MM, Butler M, Stark A, Kane RL. Multidisciplinary pain program for chronic noncancer pain: Effective Health Care Program technical brief number 8. Rockville, MD: Agency for Healthcare Research and Quality, US Department of Health and Human Services; 2011.

47. McCarberg BH, Stanos S, Williams DA. Comprehensive chronic pain management: improving physical and psychological function (CME multimedia activity). Am J Med. 2012;125(6):S1

48. Graham GG, Scott KF. Mechanisms of action of paracetamol and related analgesics. Inflammopharmacology. 2003;11(4):401-413.

49. Baron R. Neuropathic pain: a clinical perspective. Handb Exp Pharmacol. 2009;(194):3-30.

50. Seibert K, Zhang Y, Leahy K, et al. Pharmacological and biochemical demonstration of the role of cyclooxygenase 2 in inflammation and pain. Proc Natl Acad Sci U S A. 1994;91(25): 12013-12017.

51. Afilalo M, Etropolski MS, Kuperwasser B, et al. Efficacy and safety of tapentadol extended release compared with oxycodone controlled release for the management of moderate to severe chronic pain related to osteoarthritis of the knee. Clin Drug Investig. 2010;30(8): 489-505. 
52. Barkin RL, Iasco AM, Barkin SJ. Opioids used in primary care for the management of pain: a pharmacologic, pharmacotherapeutic, and pharmacodynamic overview. In: Boswell MV, Cole BE, editors. Weiner's Pain Management: A Practical Guide for Clinicians. 7th ed. New York, NY: Taylor and Francis; 2005.

53. Hall S, Gallagher RM, Gracely E, Knowlton C, Wescules D. The terminal cancer patient: effects of age, gender, and primary tumor site on opioid dose. Pain Med. 2003;4(2):125-134.

54. Vigano A, Bruera E, Suarez-Almazor ME. Age, pain intensity, and opioid dose in patients with advanced cancer. Cancer. 1998;83(6): 1244-1250.

55. Cepeda MS, Farrar JT, Baumgarten M, Boston R, Carr DB, Strom BL. Side effects of opioids during short-term administration: effect of age, gender, and race. Clin Pharmacol Ther. 2003;74(2): $102-112$.

56. Gear RW, Miaskowski C, Gordon NC, Paul SM, Heller PH, Levine JD. Kappa-opioids produce significantly greater analgesia in women than in men. Nat Med. 1996;2:1248-1250.

57. Hanlon JT, Boudreau RM, Roumani YF, et al. Number and dosage of central nervous system medications on recurrent falls in community elders: the Health, Aging and Body Composition Study. J Gerontol A Biol Sci Med Sci. 2009;64(4):492-498.

58. Schepis TS, Krishnan-Sarin S. Characterizing adolescent prescription misusers: a population-based study. J Am Acad Child Adolesc Psychiatry. 2008;47(7):745-754.

59. Fanoe S, Hvidt C, Ege P, Jensen BG. Syncope and QT prolongation among patients treated with methadone for heroin dependence in the city of Copenhagen. Heart. 2007;93:1051-1055.

60. Smith MT. Neuroexcitatory effects of morphine and hydromorphone: evidence implicating the 3-glucuronide metabolites. Clin Exp Pharmacol Physiol. 2000;27(7):524-528.

61. Angst MS, Buhrer M, Lotsch J. Insidious intoxication after morphine treatment in renal failure: delayed onset of morphine-6-glucuronide action. Anesthesiology. 2000;92(5):1473-1476.

62. Babul N, Darke AC, Hagen N. Hydromorphone metabolite accumulation in renal failure. J Pain Symptom Manage. 1995;10(3): 184-186.

63. Guay DR, Awni WM, Findlay JW, et al. Pharmacokinetics and pharmacodynamics of codeine in end-stage renal disease. Clin Pharmacol Ther. 1988;43(1):63-71.

64. Dean M. Opioids in renal failure and dialysis patients. J Pain Symptom Manage. 2004;28(5):497-504.

65. Tegeder I, Lotsch J, Geisslinger G. Pharmacokinetics of opioids in liver disease. Clin Pharmacokinet. 1999;37(1):17-40.

66. OPANA ${ }^{\circledR}$ ER (oxymorphone hydrochloride) [prescribing information]. Chadds Ford, PA: Endo Pharmaceuticals; 2012.

67. Duragesic ${ }^{\circledR}$ (fentanyl transdermal system) [prescribing information]. Raritan, NJ: Ortho-McNeil-Janssen Pharmaceuticals, Inc; 2009.

68. MS Contin ${ }^{\circledR}$ (morphine extended release) [prescribing information]. Hazelwood, MO: Mallinckrod; 2010.

69. Dubinsky RM, Kabbani H, El-Chami Z, Boutwell C, Ali H, Quality Standards Subcommittee of the American Academy of Neurology. Practice parameter: treatment of postherpetic neuralgia: an evidencebased report of the Quality Standards Subcommittee of the American Academy of Neurology. Neurology. 2004;63(6):959-965.

70. Chou R, Ballantyne JC, Fanciullo GJ, Fine PG, Miaskowski C. Research gaps on use of opioids for chronic noncancer pain: findings from a review of the evidence for an American Pain Society and American Academy of Pain Medicine clinical practice guideline. J Pain. 2009;10(2):147-159.

71. Noble M, Treadwell JR, Tregear SJ, et al. Long-term opioid management for chronic noncancer pain. Cochrane Database Syst Rev. 2010;(1):CD006605.

72. Kalso E, Edwards JE, Moore RA, McQuay HJ. Opioids in chronic non-cancer pain: systematic review of efficacy and safety. Pain. 2004;112(3):372-380.
73. Antman EM, Bennett JS, Daugherty A, Furberg C, Roberts H, Taubert KA. Use of nonsteroidal antiinflammatory drugs: an update for clinicians: a scientific statement from the American Heart Association. Circulation. 2007;115(12):1634-1642.

74. Bhamb B, Brown D, Hariharan J, Anderson J, Balousek S, Fleming MF. Survey of select practice behaviors by primary care physicians on the use of opioids for chronic pain. Curr Med Res Opin. 2006;22(9): 1859-1865.

75. Upshur CC, Luckmann RS, Savageau JA. Primary care provider concerns about management of chronic pain in community clinic populations. J Gen Intern Med. 2006;21(6):652-655.

76. Chou R, Fanciullo GJ, Fine PG, Miaskowski C, Passik SD, Portenoy RK. Opioids for chronic noncancer pain: prediction and identification of aberrant drug-related behaviors: a review of the evidence for an American Pain Society and American Academy of Pain Medicine clinical practice guideline. J Pain. 2009;10(2):131-146.

77. National Opioid Use Guideline Group (NOUGG). Canadian guideline for safe and effective use of opioids for chronic non-cancer pain. Available from: http://nationalpaincentre.mcmaster.ca/opioid/. Accessed October 1, 2013.

78. Kahan M, Wilson L, Mailis-Gagnon A, Srivastava A. Canadian guideline for safe and effective use of opioids for chronic noncancer pain: clinical summary for family physicians. Part 2: special populations. Can Fam Physician. 2011;57(11):1269-1276.

79. Butler SF, Fernandez K, Benoit C, Budman SH, Jamison RN. Validation of the revised Screener and Opioid Assessment for Patients with Pain (SOAPP-R). J Pain. 2008;9(4):360-372.

80. Butler SF, Budman SH, Fernandez KC, et al. Development and validation of the Current Opioid Misuse Measure. Pain. 2007;130(1-2): 144-156.

81. Webster LR, Webster RM. Predicting aberrant behaviors in opioidtreated patients: preliminary validation of the Opioid Risk Tool. Pain Med. 2005;6(6):432-442.

82. Kahan M, Srivastava A, Wilson L, Gourlay D, Midmer D. Misuse of and dependence on opioids: study of chronic pain patients. Can Fam Physician. 2006;52(9):1081-1087.

83. Sellers EM, Schoedel KA, Romach MK. Update on formulations to deter tampering. Presented at: College on Problems of Drug Dependence 73rd Annual Scientific Meeting; June 18-23, 2011; Hollywood, FL.

84. Gourlay DL, Heit HA, Almahrezi A. Universal precautions in pain medicine: a rational approach to the treatment of chronic pain. Pain Med. 2005;6(2):107-112.

85. Manchikanti L, Manchukonda R, Damron KS, Brandon D, McManus CD, Cash K. Does adherence monitoring reduce controlled substance abuse in chronic pain patients? Pain Physician. 2006;9(1):57-60.

86. Reisfield GM, Webb FJ, Bertholf RL, Sloan PA, Wilson GR. Family physicians' proficiency in urine drug test interpretation. J Opioid Manag. 2007;3(6):333-337.

87. Chou R, Fanciullo GJ, Fine PG, et al. Clinical guidelines for the use of chronic opioid therapy in chronic noncancer pain. J Pain. 2009;10(2):113-130.

88. Agency Medical Directors Group. Interagency on opioid dosing for chronic non-cancer pain: an educational aid to improve care and safety with opioid therapy. Available from: http://www.agencymeddirectors. wa.gov/Files/OpioidGdline.pdf. Accessed October 1, 2013.

89. Zink J. On final day, Florida lawmakers approve bill to crack down on pill mills. Tampa Bay Times. May 6, 2011. http://www.tampabay.com/ news/health/article1168138.ece. Accessed October 22, 2013.

90. US Food and Drug Administration. Approved Risk Evaluation and Mitigation Strategies (REMS). US Department of Health and Human Services. Available from: http://www.fda.gov/Drugs/DrugSafety/Postm arketDrugSafetyInformationforPatientsandProviders/ucm111350.htm. Accessed October 1, 2013. 
Journal of Pain Research

\section{Publish your work in this journal}

The Journal of Pain Research is an international, peer-reviewed, open access, online journal that welcomes laboratory and clinical findings in the fields of pain research and the prevention and management of pain. Original research, reviews, symposium reports, hypothesis formation and commentaries are all considered for publication.

The manuscript management system is completely online and includes a very quick and fair peer-review system, which is all easy to use. Visit http://www.dovepress.com/testimonials.php to read real quotes from published authors.

\footnotetext{
Submit your manuscript here: http://www.dovepress.com/journal-of-pain-research-journal
} 